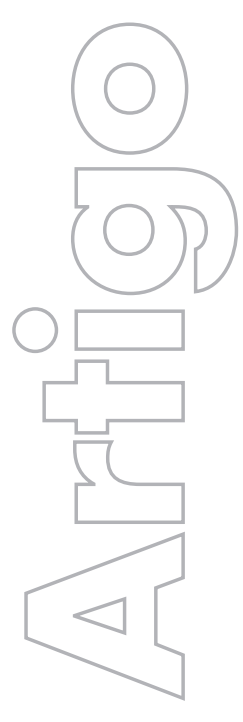

revista

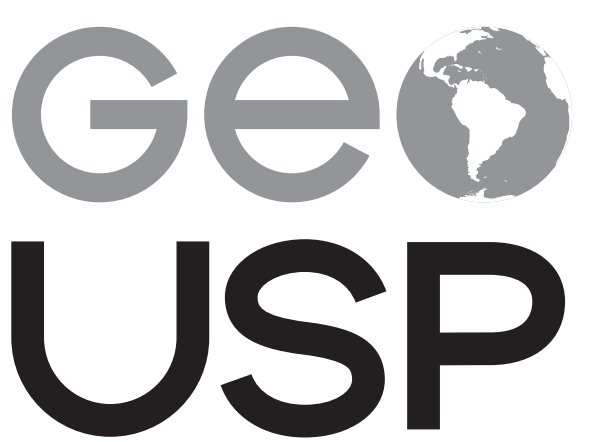

espaço e tempo

Volume $23 \cdot n^{\circ} 1$ (2019)

ISSN 2179-0892

\section{Estrutura e objetivos da transposição do rio São Francisco: versões de uma mesma história}

\section{Ana Paula Novais Pires \\ Unesp \\ e-mail: anapaulapires05@yahoo.com.br}

p. $182-197$

Como citar este artigo:

PIRES, A. P. N. Estrutura e objetivos da transposição do rio São Francisco: versões de uma mesma história. Geousp Espaço e Tempo (Online), v. 23, n. 1, p. 182-197, abr. 2019. ISSN 2179-0892.

Disponível em: https://www.revistas.usp.br/geousp/article/ view/122366. doi: https://doi.org/10.11606/issn.2179-0892. geousp.2019.122366.

\section{(C) $(1) \circledast$}

Este artigo está licenciado sob a Creative Commons Attribution 4.0 License. 


\title{
Estrutura e objetivos da transposição do rio São Francisco: versões de uma mesma história
}

\section{Resumo}

O São Francisco é o maior rio totalmente situado em território nacional. Seu curso principal é o foco da discussão sobre a transposição de águas para as bacias hidrográficas do Nordeste Setentrional. Por meio de uma abordagem qualitativa e com base em autores que debatem o tema, órgãos, entidades e seus acervos documentais sobre a transposição, este artigo visa compreender seus aspectos históricos, estruturais e políticos. Assim, transita pelas reflexões sobre a histórica pressão para que as águas do rio São Francisco resolvam os infortúnios do semiárido, de que a transposição é um reflexo. Essa transposição implica uma situação conflituosa entre o comitê gestor das águas do Velho Chico e o governo federal, já que se desconsiderou papel central desse comitê, que é contrário à transposição.

Palavras-chave: Rio São Francisco. Transposição. Semiárido. Nordeste. Bacia hidrográfica.

\section{The transposition of the São Francisco River in its structure and objectives: versions of the same story}

\begin{abstract}
The São Francisco River is the largest river fully situated in national territory. Its main course is the focus of discussions on the transposition of waters to the watersheds of the Northeast of the North. This article, through a qualitative approach, aims to understand the transposition of the São Francisco River in its historical, structural and political aspects. It is, therefore, based on authors who debate the thematic, organs, entities and their documentary collections on the transposition. The article goes to the reflections on the historical pressure so that the waters of the São Francisco River solve the misfortunes of the semiarid, being the transposition a reflection of this. The transposition represents a conflictive situation between the Old Chico water management committee and the Federal Government, since there was a disregard of the central role of the committee, which has a position contrary to the transposition.
\end{abstract}

Keywords: San Francisco River. Transposition. Northeast. Semiarid. Watershed. 


\section{Introdução}

○ uso da terra e da água na bacia hidrográfica do São Francisco motivaram o surgimento dos primeiros vilarejos, inicialmente para procurar riquezas minerais, como ocorreu na sua porção sul. No século XIX, a retirada da vegetação que margeava o rio para suprir de lenha as embarcações e, na década de 1970, a ocupação agropecuária na bacia ilustram o histórico de degradação do rio e de desmatamento dos biomas cerrado e caatinga (CBHSF, [s.d.]). A esse respeito, Gonçalves e Oliveira (2009) mencionam que, durante o século XIX, a geografia do rio São Francisco foi pauta de pesquisas descritivas sobre a fauna e a flora. Já no século XX, o rio tornou-se palco de ações de combate à seca.

A transposição do rio São Francisco ou Projeto de Integração do Rio São Francisco com as Bacias do Nordeste Setentrional (Pisf) está sendo divulgado como Projeto São Francisco, com o slogan "um Brasil mais integrado e melhor para todos", sob a tutela do governo federal, pelo Ministério da Integração Nacional. Nesse sentido, o artigo objetiva debater a transposição do rio São Francisco a partir do tripé histórico-estrutura-questões políticas. Para tanto, partindo de uma abordagem qualitativa, A referência de análise é o Comitê da Bacia Hidrográfica do Rio São Francisco (CBHSF), sendo que o fenômeno pesquisado é a transposição do rio São Francisco para as bacias hidrográficas da porção norte do Nordeste brasileiro. A construção do referencial teórico pautou-se em autores que analisam a transposição do São Francisco, como o engenheiro agrônomo João Suassuna (IHU, 2016), Castro (2011), Ab’ Sáber (2006), bem como no arcabouço documental de órgãos do governo federal, de entidades como o CBHSF. É necessário e pertinente discutir a transposição do São Francisco para entender e dialogar sobre as grandes obras hídricas no Brasil e os limites de atuação dos comitês de bacias versus políticas públicas para os recursos hídricos no contexto de fortalecimento do agro-hidronegócio.

\section{Características da área e do fenômeno estudados}

$\bigcirc$ rio São Francisco nasce na Serra da Canastra, a 1.600 m de altitude, no Chapadão da Zagaia, município de São Roque das Minas (MG), abrangendo também os estados da Bahia (BA), de Pernambuco (PE) e, em menor área, de Goiás (GO) e do Distrito Federal (DF), para desaguar no oceano Atlântico, entre Sergipe (SE) e Alagoas (AL). Ao todo, são 507 municípios em quatro trechos, Alto, Médio, Submédio e Baixo São Francisco (CBHSF, [s.d.]). É o rio da integração nacional pela abrangência de sua extensão no país, e é também conhecido como Velho Chico, pelas questões culturais, pelo simbolismo das suas águas. A área de drenagem da bacia hidrográfica do São Francisco abrange 639.219 km².

A transposição do São Francisco, orçada inicialmente em $\mathrm{R}$ \$ 8,2 bilhões, visa captar água e direcionar para dois eixos independentes: Norte e Leste, a jusante de Sobradinho (Brasil, 2006). Com 270 km de extensão de canais, o Eixo Norte captará água no São Francisco, próximo ao município de Cabrobó (PE), para o sertão dos estados de Pernambuco, Rio Grande do Norte, Ceará e Paraíba. 
Eixo Leste, por sua vez, tem captação de água iniciada no lago da Barragem de Itaparica (entre Pernambuco e Bahia), no município de Floresta (PE), até o rio Paraíba. São 217 km de canais que levarão água até parte do sertão e do agreste de Pernambuco e da Paraíba (Brasil, 2006). Os dois pontos de captação inicial da transposição distam menos de $100 \mathrm{~km}$ entre si.

Em 2011, o governo federal divulgou o planejamento da obra a partir de seis trechos (Brasil, 2006, [s.d.]b):

- Meta 1 Leste - Meta Piloto (16 km): captação no Reservatório de Itaparica até o Reservatório Areias, em Floresta (PE). Status de conclusão atual (Junho de 2016): 98,4\%. Município envolvido: Floresta (PE);

- Meta 2 Leste - (167 km): início na saída do Reservatório Areias (Floresta, PE), até o Reservatório Barro Branco, em Custódia (PE). Status de conclusão atual: 86,7\%. Municípios envolvidos: Floresta (PE), Custódia (PE) e Betânia (PE);

- Meta 3 Leste - (34km): Entre o Reservatório Barro Branco (Custódia, PE), e o Reservatório Poções (Monteiro, PB). Status de conclusão atual: 63,2\%. Municípios envolvidos: Custódia (PE), Sertânia (PE) e Monteiro (PB);

- Meta 1 Norte - (140km): captação no rio São Francisco, em Cabrobó (PE), até - Reservatório de Jati (Jati, CE). Status de conclusão atual: 86,8\%. Municípios envolvidos: Cabrobó (PE), Terra Nova (PE), Salgueiro (PE), Verdejante (PE) e Penaforte (CE);

- Meta 2 Norte - (39km): início no Reservatório Jati (Jati, CE) até o Reservatório Boi II (Brejo Santo, CE). Status de conclusão atual: 80,6\%. Municípios envolvidos: Jati, Brejo Santo e Mauriti, todos no Ceará;

- Meta 3 Norte - (81 km): do Reservatório Boi II (Brejo Santo, CE), até o Reservatório Engenheiro Ávidos (Cajazeiras, PB). Status de conclusão atual: 93,3\%. Municípios envolvidos: Brejo Santo (CE), Mauriti (CE), Barro (CE), Monte Horebe (PB), São José de Piranhas (PB) e Cajazeiras (PB).

As seis metas representam, ao todo, 16 lotes que foram licitados com contratos individuais. $\bigcirc$ setor de engenharia do exército brasileiro finalizou, em junho de 2012, a construção do canal de aproximação da captação de água e do Reservatório de Tucutu, na desembocadura desse canal, ambos em Cabrobó, Eixo Leste. A Figura 1 mostra um trecho do Submédio Rio São Francisco e os eixos da transposição. 


\section{Figura 1 - Metas das obras da transposição do São Francisco nos Eixos Norte e Leste ${ }^{1}$}

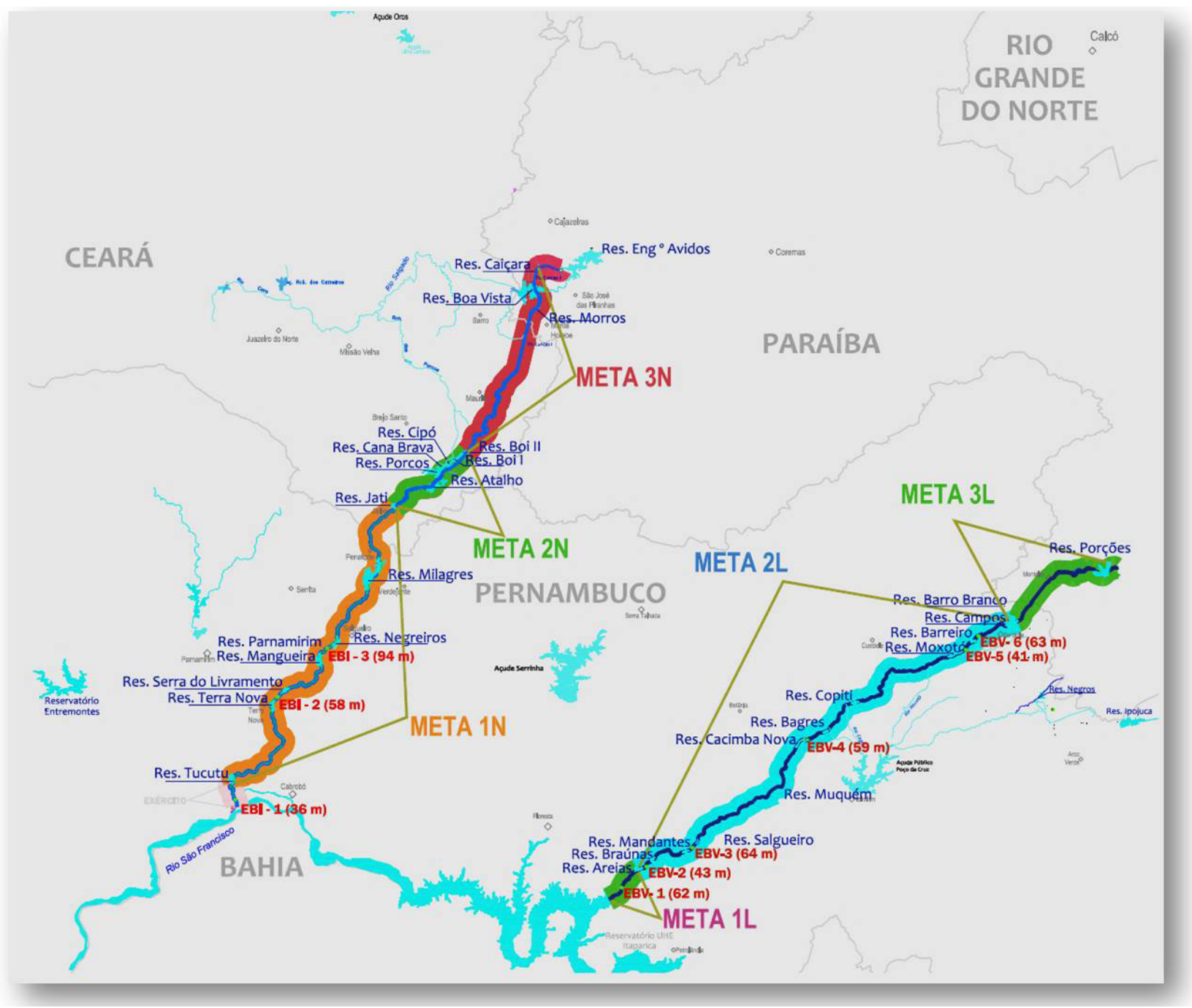

EBV - Estações de bombeamento. fonte: Brasil (2004). adaptação: Ana P. Novais Pires, 2016.

De acordo com a Figura 1, destacam-se as três estações de bombeamento do Eixo Norte, totalizando um desnível de 188 m. No Eixo Leste, são seis estações, com um desnível total de $332 \mathrm{~m}$.

Captando água a partir do Eixo Leste, na bacia do rio Moxotó, há o Sistema Adutor do Ramal do Agreste. Nesse sentido, um canal com capacidade de $8 \mathrm{~m}^{3} / \mathrm{s}$ e estações elevatórias para desníveis de $200 \mathrm{~m}$, levarão água para o açude que será construído na cabeceira do rio Ipojuca. A licença de instalação ${ }^{2}$ desse sistema foi concedida em 2013 pelo governo do estado de Pernambuco (Brasil, 2006). É preciso salientar que, como reitera Khoury (2008), o governo federal fez novos traçados que não passaram por análise e aprovação dos órgãos ambientais.

\footnotetext{
1 Além dos Eixos Norte e Leste, também existem projetos de transposição suplementar de água como o Canal do Sertão Alagoano, o Canal Oeste (entre o Piauí e Remanso, na Bahia) e o Canal do Sertão Baiano, ou Eixo Sul.

2 Licença de Instalação n. 01.13. 01.000171-1. Agência Estadual de Meio Ambiente do Pernambuco (CPRH).
} 


\section{Transposição do São Francisco: estrutura e objetivos}

$\bigcirc$ Pisf tem a prerrogativa de assegurar água para cerca de 12 milhões de pessoas no agreste e no sertão de Pernambuco, bem como no Ceará, na Paraíba e no Rio Grande do Norte. Ao todo, são 390 municípios no Nordeste Setentrional, além de 294 comunidades rurais que margeiam os canais (Brasil, 2006).

As transferências de águas entre bacias hidrográficas no contexto internacional e nacional têm como importante ator central o Banco Mundial e suas atividades no setor hídrico. Como exemplos de atuação do Banco no financiamento de transferência de águas entre bacias hidrográficas citam-se, no plano internacional, o Wanjiazhai Water Transfer Project (WWTP), na China, e o Lesotho Highlands Water Project, em Lesoto, centro-leste da África do Sul. No Brasil, o Banco Mundial financiou o Projeto de Gerenciamento e Integração dos Recursos Hídricos (PROGERIRH), criado pelo governo do Ceará em 1997, abrangendo a interligação da bacia do rio Jaguaribe com as bacias da Região Metropolitana de Fortaleza, que também é abrangida pela transposição do São Francisco (Azevedo et al., 2005).

Nos EUA, o Colorado Big Thompson Project (Projeto Colorado Big Thompson) transpõe água do rio Colorado para o Big Thompson através de $153 \mathrm{~km}$ de canais. $\bigcirc$ projeto conta com sete usinas hidrelétricas, 12 reservatórios, $56 \mathrm{~km}$ de túneis e três estações elevatórias. Seu objetivo era melhorar o setor industrial e agrícola do nordeste do Colorado, mas, posteriormente, passou a ser usado para abastecimento urbano e produção de energia hidrelétrica (Azevedo et al., 2005).

Azevedo et al. (2005) exemplificam também o Snowy Mountains Hydroelectric Scheme (Sistema Hidrelétrico das Montanhas de Snowy), na Austrália; a transposição dos rios Tajo-Segura, na Espanha; o Projeto do Canal El-Salam, Península do Sinai, no Egito; o Projeto Especial Chavimochic: rios Chao, Virú, Moche e Chicama, no Peru; Projeto Trasvase Rio Daule - Península de Santa Elena, no Equador. $\bigcirc$ caso mais conhecido é o de Aral, na Ásia Central, entre o Cazaquistão e o Uzbequistão, que teve sua área excessivamente diminuída pela redução do fluxo de água. $\bigcirc$ lago de $\mathrm{Aral}^{3}$ transformou-se numa área salinizada.

No Brasil, outras experiências em transposições entre bacias hidrográficas têm como exemplo os Sistemas Alto Tietê-Baixada Santista e Rio Piracicaba-Alto Tietê (Sistema Cantareira), em São Paulo, além da transposição do rio Paraíba do Sul, envolvendo os estados do Rio de Janeiro, São Paulo e Minas Gerais. No Nordeste, tem-se o Sistema Curema-Mãe d'Água para as Várzeas de Souza, Paraiba (empreendimento associado à transposição do São Francisco), e a transposição do rio Paraguaçu para abastecer a Região Metropolitana de Salvador (Azevedo et al., 2005).

A transposição do São Francisco caminha por um histórico percurso, sempre como pano de fundo matar a sede dos sertanejos do semiárido, expondo uma disputa geopolítica entre os estados doadores de água: Bahia, Minas Gerais e Sergipe, e os estados receptores: Ceará, Rio Grande do Norte, Paraiba e Pernambuco.

Durante o Brasil Império, houve a primeira proposta de transposição, em 1821, recomendada por D. João VI ao seu filho, Pedro I (Brasil, 2004). Em 1847, o engenheiro e deputado cearense Marcos de Macedo apresentou a D. Pedro II uma proposta de transposição para

3 Embora seja conhecido como Mar de Aral, Aral é um lago. 
amenizar a falta de água no Nordeste seco. ${ }^{4}$ Entre 1856 e 1859, a partir de estudos técnicos chefiados pelo Barão de Capanema, ${ }^{5}$ surgiu a proposta de construção de um canal de ligação entre os rios São Francisco e Jaguaribe, no Ceará. Em 1886, a construção do canal foi relembrada, mas sem prosseguimento. No período Republicano, a ideia de uma transposição teve mais ênfase e já em 1909, o então Instituto de Obras Contra as Secas (locs) propôs a ligação entres os rios São Francisco e Jaguaribe. Dez anos depois, a Inspetoria Federal de Obras Contra as Secas (Ifocs) retomou o projeto de ligação, mas não lhe deu continuidade (Castro, 2011).

A retomada e arquivamento de projetos para a transposição do São Francisco segue seu histórico percurso histórico em 1981, com o Departamento Nacional de Obras Contra as Secas (Dnocs). Já em 1993, no governo Itamar Franco, o Ministério da Integração Nacional sugeriu a construção de um canal em Cabrobó, Pernambuco, objetivando captar $150 \mathrm{~m}^{3}$ de águas do Velho Chico para favorecer os estados do Ceará e do Rio Grande do Norte. Entretanto, em 1994, o Tribunal de Contas da União (TCU) não aprovou o projeto (Castro, 2011).

Nos governos de Fernando Henrique Cardoso, desde 1995, tanto o Ministério da Integração quanto a Companhia de Desenvolvimento do Vale do São Francisco (Codevasf) firmaram propostas. As ideias atuais da transposição ganharam fôlego com o primeiro mandato de Luiz Inácio Lula da Silva (2003-2006) (Castro, 2011). Scarpin (2012) avalia que são poucas as diferenças do projeto de transposição entre os governos Fernando Henrique e Lula. A vazão pretendida no projeto da era Fernando Henrique captaria $64 \mathrm{~m}^{3} / \mathrm{s}$, sendo que $71 \%$ seriam destinados à irrigação, 25\% ao consumo urbano e 4\% para perdas do sistema e demais consumos, objetivando inserir o Nordeste Setentrional na agricultura irrigada para exportação.

Em 2004, foi instituído um grupo interministerial formado pelo Ministério da Integração Nacional, Ministério de Minas e Energia (MME), Ministério de Meio Ambiente (MMA), além de órgãos como a Companhia Hidrelétrica do São Francisco (Chesf) e a Agência Nacional de Águas (ANA).

Com a Resolução Federal n. 29, de 24 de Janeiro de 2005, a ANA aprovou a outorga preventiva para a transposição. Já com a Resolução Federal n. 411, de 26 de setembro de 2005, a ANA outorgou ao Ministério da Integração Nacional o direito de captar por 20 anos água do São Francisco para a transposição. Nesse mesmo dia, pela Resolução Federal n. 412, a ANA emitiu o Certificado de Avaliação da Sustentabilidade da Obra Hídrica (Certoh) atestando a sustentabilidade hídrica, operacional e financeira da transposição (Brasil, 2006).

Entre as condições descritas na Resolução Federal n. 411/2005, constam em seu artigo 10, parágrafo IV, a captação firme e contínua ( $24 \mathrm{~h} /$ dia) de $26,4 \mathrm{~m}^{3} / \mathrm{s}^{6}$ e captação instantânea de $127 \mathrm{~m}^{3} / \mathrm{s}$ quando o reservatório de Sobradinho estiver em condições muito favoráveis de água.

Ainda em 2005, o Instituto Brasileiro de Meio Ambiente e Recursos Naturais Renováveis (Ibama) emitiu um parecer sobre o Relatório de Impactos Ambientais da transposição (Rima-Pisf) e a licença prévia para as obras. Em 2007, foi concedida a licença de instalação de quatro anos (Brasil, 2006).

4 Correspondente ao que hoje se chama de semiárido nordestino.

5 Guilherme Schuch de Capanema, o Barão de Capanema, foi um engenheiro e físico brasileiro que chefiou a Comissão Científica de Exploração na segunda metade do século XIX.

6 Equivale a 1,4\% da vazão garantida por Sobradinho no trecho do rio onde se captará a água para a transposição. 
Assim, tendo o rio São Francisco como cenário responsável por 63\% da oferta hídrica nordestina, partiu-se do campo das ideias para o canteiro de obras em 2007, no segundo mandato do presidente Lula (2007-2010). A captação de água será feita por canais artificiais de concreto de $50 \mathrm{~m}$ de largura e $15 \mathrm{~m}$ de altura. Do total captado, são $16,4 \mathrm{~m}^{3} / \mathrm{s}$ para o Eixo Norte, que tem capacidade total para $99 \mathrm{~m}^{3} / \mathrm{s}$, e $10 \mathrm{~m}^{3} / \mathrm{s}$ para o Eixo Leste, com capacidade total para $28 \mathrm{~m}^{3} / \mathrm{s}$ (Brasil, 2006).

Brasil (2004) expõe que o projeto está vinculado ao Plano Plurianual 2004-2007 Brasil de Todos, do governo federal, e associa-se a outros empreendimentos como a construção de adutoras a partir de açudes que receberão águas da transposição, objetivando suprir a demanda urbana. A construção de açudes como o Santa Cruz (no rio Apodi), Acauã (no rio Paraíba) e Castanhão (no rio Jaguaribe), também são citados como articulações do governo federal com as obras da transposição. Além disso, os governos do Ceará, do Rio Grande do Norte e da Paraíba, como associação à transposição, investiram na construção do Canal do Castanhão (ligação do açude Castanhão às bacias hidrográficas metropolitanas de Fortaleza), de perímetros irrigados vinculados a açudes e no Canal da Redenção (ligando o açude Curema-Mãe d’Água às Várzeas de Souza, PB).

Segundo Nunes (2014), é importante destacar que os Planos Plurianuais são avaliados pelo Banco Mundial na concessão de empréstimos ao Brasil, sendo que o Programa de Aceleração do Crescimento (PAC), que inclui a transposição, tem investimentos do Banco. Nunes (2014, p. 69) considera a atuação do Estado na transposição do São Francisco "[...] uma política para o reordenamento territorial do espaço agrário do sertão nordestino". $\bigcirc$ autor ainda aborda as intervenções do Banco Mundial no setor de gestão hídrica, irrigação e o combate à seca no Nordeste, bem como o domínio das águas perenes no semiárido pelo capital nacional e estrangeiro, que controlam a produção agrícola regional.

Ressalta-se que o Projeto São Francisco não abastecerá a população difusa no meio rural, ou seja, não vai acabar com a utilização de carros pipa. Suassuna e Abner (Opinião [...], 2013) analisam que a transposição apenas transfere água do São Francisco para açudes da região receptora, por exemplo, o Castanhão, o maior do Nordeste. Nesse contexto, os sistemas de distribuição de água serão executados pelos governos estaduais, com apoio financeiro de $\mathrm{R} \$$ 285 milhões do governo federal (Brasil, 2006).

Os canais deverão ser cercados para evitar acesso direto de animais e pessoas, já que "[...] isso aqui não vai ser um rio para quem quiser vir e pegar água", segundo um dos engenheiros responsáveis pela vistoria das obras da transposição em Floresta, Pernambuco, em entrevista à revista Piauí (Scarpin, 2012).

Destaca-se que, de acordo com o PAC ([s.d.]), o Eixo Leste tem atualmente um investimento financeiro em obras previsto de $\mathrm{R} \$ 3.463 .294 .813,27$ e o Eixo Norte, de $\mathrm{R} \$$ 6.127.754.266,92. Os recursos empregados têm previsão de retorno a partir da cobrança pela captação das águas, sendo que a ANA definirá o valor da água por $\mathrm{m}^{3}$ e os estados beneficiados terão que arcar com os custos de manutenção da transposição. 
Segundo o Rima-Pisf (Brasil, 2004), serão beneficiadas, no Nordeste Setentrional, as bacias hidrográficas Brígida, Terra Nova, Pajeú, Moxotó (PE), Jaguaribe e as bacias metropolitanas de Fortaleza, formadas por 16 sub-bacias, além das bacias dos rios Apodi e Piranhas-Açu (RN) e Paraiba e Piranhas (PB). Destaca-se que as bacias Brígida e Moxotó são sub-bacias do São Francisco.

Para a cobrança dos custos operacionais do empreendimento, na porção final de Jusante de cada ponto de entrega de água nos estados receptores, está prevista a implantação de medidores de volume (Ibama, 2005). Ademais, a Sociedade Brasileira para o Progresso da Ciência (SBPC, 2004) reforça que o custo final da água transposta por metro cúbico seria estimado pela divisão do custo total da transposição pela vazão total a ser transposta durante a vida útil econômica do empreendimento.

Nesse contexto, em 2010, o CBHSF atualizou os mecanismos e os critérios de cobrança pela alocação externa entre os Eixos. A Deliberação CBHSF n. 51/20107 definiu as diferentes equações de valores até a entrada em operação da transposição e após repartição das vazões entre as concessionárias de abastecimento dos estados receptores.

No Eixo Norte, os rios beneficiados pela transposição são Brígida (PE), Salgado (CE), Peixe e Piranhas-Açu e Apodi (RN). No Ceará, o rio Jaguaribe e as bacias hidrográficas metropolitanas de Fortaleza serão interligados pelo Canal do Trabalhador. Nesse sentido, os açudes beneficiados serão Chapéu, Pau dos Ferros Santa Cruz e Armando Ribeiro Gonçalves $(\mathrm{RN})$, Entre Montes (PE), Castanhão (CE), Engenheiro Ávidos e São Gonçalo (PB).

No Eixo Leste, o rio Paraiba, uns dos beneficiados, é responsável pela manutenção do açude Epitácio Pessoa, conhecido como Boqueirão. $\bigcirc$ estado mais beneficiado pela transposição será a Paraiba, que tem o maior deficit hídrico do Nordeste. Os dois Eixos somarão nove subestações de 230 quilowatts e $270 \mathrm{~km}$ de linhas de transmissão, além de três aquedutos, nove estações de bombeamento, 27 reservatórios e quatro túneis ${ }^{8}$ (Brasil, 2004).

\section{Transposição do São Francisco: dos aspectos contraditórios com a revita- lização da bacia}

A escolha do São Francisco foi justificada no Rima-Pisf(Brasil, 2004, p. 33) "[...] porque esse rio é a maior e a mais próxima fonte de água doce perene da região", e as outras possibilidades de suprimento de água eram limitadas, caras e/ou apenas complementares à transposição, como poços, cisternas, açudes e a dessalinização. Para Ab'Sáber (2006, p. 10), "ao se iniciar a ideia da transposição de águas do São Francisco para o Ceará e Rio Grande do Norte, ninguém se preocupou com os problemas da própria região de onde sairiam as águas", na porção fisiográfica do Submédio. Tampouco foram levadas em conta as experiências de sucesso já existentes no semiárido de captação e reserva de água das chuvas em cisternas de placas de concreto ${ }^{9}$ e apoio técnico aos pequenos agricultores.

7 Primeiramente, a questão foi definida pela Deliberação do CBHSF n. 45/2009.

8 O túnel Cuncas I é o maior da América Latina para transporte de água, com $15 \mathrm{~km}$ de extensão. $\bigcirc$ túnel levará água do Reservatório de Mauriti (CE) ao de São José de Piranhas (PB) (Brasil, 2004).

9 Destacam-se a ONG Articulação no Semiárido Brasileiro e o programa de construção de cisternas de placas de concreto nas áreas rurais (ASA, [s.d.]). 
Nesse sentido, Castro (2011), Sarmento (2006) e Suassuna e Abner (Opinião [...], 2013) confirmam que o Nordeste Setentrional tem água suficiente para atender à sua demanda, o que foi reforçado pelo Plano Decenal de Recursos Hídricos da Bacia Hidrográfica do Rio São Francisco (PRHSF 2004-2013). Para tanto, analisando a oferta e a demanda hídrica dos múltiplos usos nas bacias receptoras da transposição (em 2005, 2010 e 2025), Castro (2011, p. 16) mostra dados por Unidade de Planejamento Hídrico ${ }^{10}$ dos estados, alicerçado na edição de 2006 do Atlas Nordeste de Abastecimento Urbano da ANA. Assim, quanto às bacias receptoras no Ceará, verificou um deficit hídrico apenas no baixo rio Jaguaribe e "[...] nas bacias metropolitanas, apenas no cenário de demanda de 2025 é que existe a perspectiva de a vazão disponível endógena dessa região não atender à demanda".

Castro (2011) afirma que entre as bacias receptoras dos rios Paraiba e Piranhas constatou-se um deficit hídrico em duas sub-bacias do Paraiba. Nas bacias receptoras pernambucanas, Brígida e Terra Nova, no Eixo Norte, e duas Unidades de Planejamento na bacia do Moxotó, Eixo Leste, apresentaram deficit. Ainda de acordo com o autor, no Rio Grande do Norte não há deficit hídrico no período analisado, pois, na bacia do Apodi-Mossoró, a vazão disponível é cinco vezes superior à máxima demanda total no cenário para 2025. Na bacia do Piranhas-Açu, a vazão é três vezes maior que a demanda total no mesmo cenário tendencial. As duas bacias concentram mais de $90 \%$ dos recursos hídricos do estado.

É preciso observar que o Atlas Nordeste de Abastecimento Urbano (Brasil, 2006) está em consonância com as informações do relatório do debate sobre a transferência de águas entre bacias, da SBPC. Suassuna (IHU, 2016) esclarece que, a partir de dados sobre recursos hídricos nas 70.000 represas nordestinas, o Atlas fomentou a possibilidade de abastecimento em municípios de até cinco mil habitantes, beneficiando o total de 34 milhões de pessoas. $O$ projeto proposto pela ANA tinha orçamento menor e maior alcance do que a transposição.

Suassuna e Abner (Opinião [...], 2013) avaliam que é falho o caráter social abordado pela transposição, já que existe água no Nordeste Setentrional que poderia atender à demanda local, o que também é discutido pela SBPC (2004), quando considera que os estados contemplados pelas águas da transposição são autossuficientes em recursos hídricos, com dados reconhecidos nos planos hídricos estaduais. Além disso, não há identificação dos projetos de irrigação beneficiários das águas da transposição, assim como a taxa de crescimento urbano para novas demandas, adotada pelo projeto de transposição na região receptora, superou a taxa histórica, demonstrando um superdimensionamento das futuras necessidades.

Castro (2011), Khoury e Reis (2005) e Sarmento (2006) ponderam que a vazão máxima alocável" de uso consuntivo médio anual na bacia, que é de $360 \mathrm{~m}^{3} / \mathrm{s}$, adotada pelo PRHSF 2004-2013 e pela Deliberação CBHSF n. 18/2004, seria suficiente para atender às demandas internas e externas da bacia.

10 "[...] uma Unidade de Planejamento Hídrico é definida como uma região hidrográfica com características relativamente homogêneas, onde as disponibilidades e demandas hídricas são conhecidas e suficientes para efetuar o balanço hídrico" (Castro, 2011, p. 15).

11 A vazão máxima alocável na bacia do rio São Francisco para diversos usos corresponde à diferença entre a máxima vazão regularizável e a vazão mínima remanescente, ambas na foz do rio São Francisco, e é de $1.300 \mathrm{~m}^{3} / \mathrm{s}$ (CBHSF, [s.d.]). 
Entretanto, da vazão alocável de $360 \mathrm{~m}^{3} / \mathrm{s}$, encontravam-se já outorgados pela ANA e pelos órgãos gestores estaduais $335 \mathrm{~m}^{3} / \mathrm{s}$, antes mesmo de o projeto de transposição ser definido, restando $25 \mathrm{~m}^{3} / \mathrm{s}$ alocáveis. Desse modo, Khoury e Reis (2005) questionam como se poderão atender as demandas da transposição $\left(26,4 \mathrm{~m}^{3} / \mathrm{s}\right.$ a $\left.127 \mathrm{~m}^{3} / \mathrm{s}\right)$ sem comprometer as outorgas já existentes, uma vez que, com a "concessão da outorga para o Projeto de Transposição de $26,4 \mathrm{~m}^{3} / \mathrm{s}$, foi criado um déficit de $1,4 \mathrm{~m}^{3} / \mathrm{s}$ do volume alocável" (Castro, 2011, p. 22).

Segundo o PRHSF (CBHSF, [s.d.], p. 139), tomando por base a vazão outorgada de $335 \mathrm{~m}^{3} / \mathrm{s}$, apesar de haver outorgas concedidas e não utilizadas, em longo prazo, não haverá água disponível sem a criação de novos conflitos para atender as áreas irrigáveis potenciais da bacia. A vazão alocável só poderá ser modificada após uma revisão das outorgas.

Suassuna e Abner (Opinião [...], 2013) reiteram que a retirada de água do Velho Chico por adutoras ou tubulações para abastecimento em locais de escassez comprovada está prevista no PRHSF 2004-2013. Desconsiderando a vazão alocável do PRHS F 2004-2013, o governo federal buscou o órgão máximo do Sistema Nacional de Gerenciamento de Recursos Hídricos (SINGREH), o Conselho Nacional de Recursos Hídricos (CNRH), resultando na aprovação integral do projeto de transposição, em única sessão e em regime de urgência, em 2005.

Das discussões sobre justificativas para levar água do São Francisco para o Nordeste Setentrional e suas reais necessidades, em contraponto ao PRHSF 2004-2013, então em vigor, passa-se aos efeitos colaterais da transposição, elencados pelo Rima-Pisf (Brasil, 2004) e pelo Parecer Federal n. 031/2005, do Ibama.

Assim, o Rima do empreendimento delimitou os impactos na área de influência direta (AID), área diretamente afetada (ADA) e área de influência indireta (AII). Tanto a bacia hidrográfica do São Francisco quanto as bacias receptoras dos rios Jaguaribe, Piranhas-Açu, Apodi e Paraiba foram consideradas de influência indireta pelo Rima. Foram identificados 44 impactos, sendo 23 de grande relevância (11 negativos e 12 positivos) (Brasil, 2004).

Os impactos positivos mais divulgados mencionam o aumento da oferta hídrica nas bacias receptoras e, desse modo, abastecimento urbano e rural, dinamização da agricultura e da economia regional. Os impactos negativos envolvem não só as intervenções nas bacias receptoras no tocante à biologia aquática e à drenagem fluvial como as mudanças nas relações socioculturais, até mesmo antes do início das obras, por exemplo, o reassentamento de populações que viviam no entorno do empreendimento e a regularização fundiária no entorno dos canais, que foi paralisada pelo Ministério Público Federal (MPF). O Ministério da Integração Nacional cita 38 programas socioambientais (Brasil, 2006), previstos nas condicionantes do Ibama para execução da transposição.

Entre as exposições do Ibama (2005) sobre o Rima-Pisf (Brasil, 2004) destacam-se: a desconsideração das alternativas de convivência e aproveitamento dos recursos hídricos no semiárido; pouca informação quanto às áreas suscetíveis a desertificação e a processos erosivos no entorno das obras; insuficiência de estudos limnológicos; impossibilidade de analisar os impactos reais na Caatinga, que ocupa mais de $80 \%$ de área de influência direta; subdimensionamento dos impactos nas áreas preservadas ao longo do empreendimento; perda de habitat da fauna; modificação nos regimes fluviais no rio São Francisco e nas drenagens receptoras, com alterações hidrossedimentológicas; redução da produção hidrelétrica pelo São Francisco, assim 
como desconsideração de comunidades indígenas, ribeirinhas e quilombolas no São Francisco. Apesar das apreciações elencadas, em 2005, o Ibama concedeu licença prévia e, em 2013, a licença de instalação para os trechos I e II do Eixo Norte, e trecho V do Eixo Leste. ${ }^{12}$

Entre as controvérsias no projeto de transposição e o desvelar dos usos da água numa perspectiva real, Nunes (2014) observa que houve crescimento superior ao brasileiro dos estabelecimentos agropecuários na macrorregião de Pernambuco (baseado no Censo Agropecuário de 1995 a 2006), enfatizando os municípios abrangidos pelos canais da transposição, como Cabrobó, Floresta, Custódia e Sertânea. $\bigcirc$ autor ainda discute a tentativa do governo federal de transformar o semiárido numa promissora fronteira agrícola, o que é corroborado pela identificação de áreas irrigáveis ao longo dos canais. Nessa lógica, Malvezzi (2015) afirma que a expansão dos projetos de irrigação no semiárido nordestino tem como vitrine o polo Juazeiro-Petrolina (Bahia-Pernambuco). Outro ponto de análise são os usos futuros da água na região do complexo industrial e portuário de Pecém (Região Metropolitana de Fortaleza), que receberá as águas do São Francisco pelo Eixo Norte, no rio Jaguaribe e no açude Castanhão (Ceará), assim como os usos para a carcinicultura no Ceará e no Rio Grande do Norte.

Destaca-se ainda a atuação da Codevasf na conclusão e no funcionamento da transposição, pois, a partir de 2014, a empresa pública passou a exercer as atividades de operação, gestão, manutenção e recebeu do Ministério da Integração Nacional toda a infraestrutura da transposição (Nunes, 2014). Assim, a "[...] Codevasf para gerenciar as águas do São Francisco é colocar a raposa dentro do galinheiro", afirma João Suassuna (IHU, 2016). Cumpre advertir que a empresa viabiliza projetos de irrigação na bacia do São Francisco por meio de parcerias público-privadas.

A pressão em favor do rio São Francisco baseada em seu histórico percurso de desmatamento da vegetação ciliar e assoreamento, assim como a poluição das águas por esgoto doméstico e pela entrada massiva do capital, iniciada com a CHESF em 1945 e, posteriormente, com o Reservatório de Sobradinho, de 1975 a 1979, e os polos de irrigação, trouxe à tona o tema da revitalização da bacia.

Desse modo, o Ministério da Integração Nacional, por meio de seu órgão executivo, a Codevasf, iniciou em 2004 o Programa de Revitalização da Bacia Hidrográfica do Rio São Francisco (PRSF), uma espécie de atenuante ao projeto de transposição. Segundo a Codevasf ([s.d.]), com recursos da União e em parceria com os estados e os municípios, a revitalização ${ }^{13}$ estrutura-se em cinco componentes temáticos:

- gestão e monitoramento ambiental, ordenamento territorial e sistema de informações georreferenciadas;

- agenda socioambiental;

- proteção e uso sustentável dos recursos naturais;

- qualidade e saneamento ambiental;

- economias sustentáveis (turismo e agricultura sustentáveis, gestão dos recursos pesqueiros).

12 Licença de Instalação n. 925/2013, concedida ao Pisf pelo Ibama.

13 Em 2005, o bispo do município de Barra (BA), Dom Luiz Cappio, iniciou uma greve de fome em protesto contra o projeto da transposição, ato repetido em 2007, contra o início das obras. A mobilização de Cappio também procurava fortalecer os projetos de convivência com o semiárido e a revitalização da bacia do rio São Francisco. 
Zellhuber e Siqueira (2007, p. 8, grifo do original) consideram que o programa de revitalização do governo federal é tímido, não vai às raízes dos problemas, funcionando mais como moeda de troca da transposição, oferecida aos críticos desta e ao povo da bacia que resiste a aceitá-la. Carvalho (2005) também ressalva que a revitalização pode resolver problemas geograficamente pontuais como recomposição da mata ciliar, saneamento básico, controle de efluentes, contudo, não vai aumentar a vazão média do rio. Nesse sentido, para Ab'Sáber (2006, p. 6), a revitalização da bacia do São Francisco só foi engendrada após a pressão para a transposição sair do papel, quando "[...] se percebeu a grandiosidade do erro em termos sociais e políticos, passou-se a falar, entre os maiores interessados na implantação do projeto, em uma revitalização prévia do Vale do Rio São Francisco".

Evidencia-se que o uso econômico da bacia, voltado para a agricultura irrigada, e a produção de energia inibe sua revitalização; segundo o PRHSF 2016-2025, pastagens e campos agrícolas representam, na atualidade, a classe de vegetação predominante na bacia, com 37\% de cobertura. Na porção do Médio São Francisco, a desertificação causada por processos erosivos já foi apontada no PRHSF 2016-2025, e se constataram o desmatamento das margens dos rios, a mecanização da agricultura e a desagregação dos solos.

Em junho de 2016, no governo de Michel Temer, a Secretaria de Recursos Hídricos e Ambiente Urbano do MMA assegurou a criação do Conselho Gestor da Revitalização do VeIho Chico, e só nesse ano o CBHSF pôde participar das decisões sobre a revitalização.

Em 2004, em meio à discussão sobre a transposição e a revitalização da bacia hidrográfica do São Francisco, a entidade civil Fórum Permanente de Defesa do São Francisco (membro do Comitê) suscitou no CBHSF um conflito pelo uso da água, considerando os impactos na gestão hídrica e no meio ambiente, sendo deliberado pelo Comitê sob o Processo Administrativo n. 001/2004. Os citados do Processo foram a União, por meio do Ministério da Integração Nacional, o MMA, o lbama e a ANA.

\section{Considerações finais}

A forma como está sendo conduzido o projeto de transposição do São Francisco implica ambiguidade socioambiental, política e até conceitual, segundo Suassuna (Água [...], 2001). Para o autor, o governo federal propôs um recalque das águas do rio que significa adução, e não propriamente uma transposição, que engloba a consideração das características ambientais da fonte supridora de água, seus potenciais transpositórios. No Brasil, as grandes obras em todos os setores trazem à tona a materialização de projetos que atropelam questões socioambientais, mas atendem ao marketing político-partidário.

O CBHSF abriu uma discussão sobre o conflito hídrico e judicializou a questão. Entretanto, um comitê só pode atuar em conflitos na totalidade de sua bacia hidrográfica, conforme descreve o Capítulo III da Política Nacional dos Recursos Hídricos (PNRH). A transposição envolve a bacia hidrográfica do São Francisco e as dos rios receptores no Nordeste Setentrional: Brígida, Terra Nova, Pajeú, Moxotó e bacias do Agreste (PE), Jaguaribe e Metropolitanas 
(CE), Apodi e Piranhas-Açu (RN) e Paraiba e Piranhas (PB). Destarte, pela PNRH, o CBHSF não é um fórum representativo de usos da água entre diferentes bacias, mostrando que a transposição levanta um conflito que extrapola a divisão administrativa do CBHSF e que não está previsto na legislação brasileira.

O caso da transposição do São Francisco e o conflito entre comitês de bacias hidrográficas interestaduais não é o único no país, mas ainda não há jurisprudência do Supremo Tribunal Federal para tratar a demanda.

Quando a transposição estiver ocorrendo, será possível observar como se ordenará essa solução para os infortúnios do Nordeste semiárido. Como o fenômeno pesquisado está em curso, o que se pode compreender até aqui é o papel já definido do CBHSF, de fiscalizar o uso da água a partir do estipulado na outorga da ANA. O percurso histórico da indústria da seca e as grandes obras hídricas de cunho eleitoreiro, como a transposição, reiteram que as potencialidades hídricas no semiárido nordestino foram sempre subavaliadas em favor de soluções milagrosas para as mazelas da região, estigmatizada como cenário de pobreza e sertanejos sofredores.

Além disso, é preciso considerar os impactos dos novos cenários propostos com a agricultura irrigada a partir das águas da transposição, notadamente no que se refere à salinização dos solos, que pode destruir não só a estrutura do perfil do solo, mas também sua compactação e, assim, inviabilizar as atividades agrícolas. No Nordeste semiárido, a baixa pluviosidade e as altas temperaturas são agravantes.

\section{Referências}

AB'SÁBER, A. N. A transposição de águas do São Francisco: análise crítica. Revista USP, São Paulo, n. 70, p. 6-13, jun./ago. 2006.

ÁGUA potável no semiárido: escassez anunciada (2001). Recife, 2001. Disponível em: http:// www.fundaj.gov.br/docs/tropico/desat/potavel.html. Acesso em: 26 jun. 2014.

ANA. AGÊNCIA NACIONAL DE ÁGUAS. Resolução n. 29, de 18 de janeiro de 2005. Disponivel em: http://www2.ana.gov.br/Paginas/institucional/SobreaAna/resolucoesana.aspx?Ano=2005. Acesso em: 10 abr. 2016.

ASA, ARTICULAÇÃO SEMINÁRIO BRASILEIRO. Disponível em: http://www.asabrasil. org.br/. Acesso em: 28 abr. 2016.

AZEVEDO, L. G. T.; PORTO, R. L.; MÉLLO JÚNIOR, A. V.; PEREIRA, J. G.; ARROBAS, D. L. P.; NORONHA, L. C.; PEREIRA, L. P. Transferência de água entre bacias hidrográficas. Brasilia: Banco Mundial, 2005.

BRASIL. Ministério do Desenvolvimento Regional. 38 programas ambientais. 2019. Disponível em: http://www.mi.gov.br/projeto-rio-sao-francisco/meio-ambiente-preservado/38-programas-ambientais. Acesso em: 26 mar. 2019. 
BRASIL. Ministério da Integração Nacional. Atlas Nordeste Abastecimento Urbano de Água 2006. Disponível em: http://www.integracao.gov.br/documents/10157/3678963/Atlas+Norrdeste+-+Abastecimento+Urbano+de+\%C3\%81g ua.pdf/8le3a0c7-2b28-4d3e-9dd7-cd9a9ba3e50e. Acesso em: 19 abr. 2015.

BRASIL. Licença Prévia n. 200, de 2005. Disponível em: http://www.mi.gov.br/documents/10157/3675235/LICENCA+PREVIA+IBAMA+200+2005.pdf/557dlc3dba2c-4564-8554-4403eeb3b317. Acesso em: 15 maio 2016.

BRASIL. Ministério da Integração Nacional. Relatório de Impactos Ambientais do Projeto de Integração do Rio São Francisco com Bacias Hidrográficas do Nordeste Setentrional. Brasilia: Ministério do Meio Ambiente, 2004.

BRASIL. Ministério do Desenvolvimento Regional. Projeto São Francisco. [s.d.]a. Disponível em: http://www.integracao.gov.br/. Acesso em: 19 abr. 2015.

BRASIL. Projeto São Francisco e o andamento das obras. [s.d.]b. Disponível em: http://www.mi.gov.br/web/projeto-sao-francisco/o-andamento-das-obras. Acesso em: 12 jun. 2016.

CARVALHO, E. T. O condomínio da transposição. In: As águas da política: razões contra a transposição das águas do rio São Francisco. Salvador: Rede Marinho-Costeira e Hídrica do Brasil, 2005. p. 60-78.

CASTRO, C. N. Transposição do rio São Francisco: análise de oportunidade do projeto. Rio de Janeiro: Ipea, 2011.

CBHSF. COMITÊ DA BACIA HIDROGRÁFICA DO RIO SÃO FRANCISCO. Plano de Recursos Hídricos da Bacia Hidrográfica do Rio São Francisco 20042013. Salvador, 2004a. Disponível em: http://www.saofrancisco.cbh.gov.br/_docs/planos/PlanoDecenaldeRecursosHidricos.pdf. Acesso em: 20 abr. 2014.

CBHSF. COMITÊ DA BACIA HIDROGRÁFICA DO RIO SÃO FRANCISCO. Deliberação CBHSF n. 18, de 27 de outubro de 2004b. Define limites, prioridades e critérios de alocação e outorga para usos externos à bacia, como parte integrante do Plano de Recursos Hídricos da Bacia Hidrográfica do Rio São Francisco. Disponível em: http:// cbhsaofrancisco.org.br/?wpfb_dl=612. Acesso em: 20 abr. 2014.

CBHSF. COMITÊ DA BACIA HIDROGRÁFICA DO RIO SÃO FRANCISCO. A bacia. Belo Horizonte, [s.d.]. Disponível em: http://cbhsaofrancisco.org.br/2017/abacia/\#caracteristicas. Acesso em: 8 abr. 2019.

CODEVASF. COMPANHIA DE DESENVOLVIMENTO DOS VALES DO SÃO FRANCISCO E DO PARNAÍBA. Disponível em: http://www.codevasf.gov.br/. Acesso em: 20 jul. 2015.

GONÇALVES, C. U.; OLIVEIRA, C. F. Rio São Francisco: as águas correm para o mercado. Boletim Goiano de Geografia, Goiânia, v. 29, n. 2, p. 113-125, jul./dez. 2009. Disponível em: https://dialnet.unirioja.es/descarga/articulo/4785683.pdf. Acesso em: 10 abr. 2014. 
IBAMA. INSTITUTO DE MEIO AMBIENTE E RECURSOS NATURAIS RENOVÁVEIS. Parecer n. 031, de 2005. Disponível em: http://www.mi.gov.br/documents/10157/3675235/PARECER+031+2005. pdf/5f8f2923-3d95-4366-bc6523955ecf2f09. Acesso em: 15 maio 2016.

IBAMA. INSTITUTO BRASILEIRO DO MEIO AMBIENTE E DOS RECURSOS NATURAIS RENOVÁVEIS. Disponível em: http://www.ibama.gov.br/. Acesso em: 20 mar. 2015.

IHU. INSTITUTO HUMANITAS UNISINOS. Transposição do São Francisco: o elefante branco nordestino? Entrevista especial com João Suassuna. São Leopoldo, RS: 17 fev. 2016. Disponível em: http://www.ihu.unisinos.br/entrevistas/551677-transposicao-do-sao-francisco-o-elefante-branco-nordestino-entrevista-especial-com-joao-suassuna. Acesso em: 8 abr. 2019.

KHOURY, L. E. C. As ilegalidades do projeto de transposição e a violação do Estado Democrático de Direito. In: DIAS, D.; CASTRO, G.; SAID, M.; GONÇALVES, A. A vida por um rio. Fortaleza: Frente Cearense Por Uma Nova Cultura da Água e Contra a Transposição das Águas do Rio São Francisco, 2008. p. 43-47.

KHOURY, L. E. C.; REIS, A. C. R. Aspectos jurídicos do projeto de transposição do Rio São Francisco. In: As águas da política: razões contra a transposição das águas do rio São Francisco. Salvador: Rede Marinho-Costeira e Hídrica do Brasil, 2005. p. 97-107.

MALVEZZI, R. A perenidade do rio São Francisco está cada vez mais ameaçada. São Leopoldo, RS: Instituto Humanitas Unisinos, 18 nov. 2015. Entrevista à Asacom.

NUNES, P. P. L. Transposição do rio São Francisco: a funcionalidade do Estado capitalista no simulacro das políticas de reordenamentos territoriais. Dissertação (Mestrado em Geografia) - Universidade Federal do Sergipe, Aracaju, 2014.

OPINIÃO Pernambuco. Transposição do Rio São Francisco. Recife, 22 jul. 2013. Entrevista com João Suassuna e João Abner Guimarães Junior. Disponível em: https://www.youtube.com/watch?v=merlNiEJORM. Acesso em: 8 abr. 2019.

PAC. PROGRAMA DE ACELERAÇÃO DO CRESCIMENTO. Projeto de Integração do Rio São Francisco com as Bacias do Nordeste Setentrional. Disponível em: http://www.pac.gov.br/infraestrutura-social-e-urbana/recursos-hidricos. Acesso em: 28 jun. 2016.

RIMA-PISF. Relatório de Impactos Ambientais do Programa de Integração da Bacia Hidrográfica do Rio São Francisco com bacias do Nordeste Setentrional. Disponível em: http://www.mi.gov.br/documents/10157/3675235/RIMA. pdf/c7f4834d-2ca8-4baf-9bbd-21cacb64ca2f. Acesso em: 5 jan. 2015.

SARMENTO, F. J. A integração do São Francisco: verdade e mito. Revista USP, São Paulo, n. 70, p. 14-23, jun./ago. 2006. 
SBPC. SOCIEDADE BRASILEIRA PARA O PROGRESSO DA CIÊNCIA. Encontro Internacional sobre Transferência de Águas entre Grandes Bacias Hidrográficas. Recife, 2004. Disponível em: http://www.abes.al.org.br/sbpcl.PDF. Acesso em: 25 mar. 2016.

SCARPIN, P. Era uma vez a transposição. Revista Piauí, São Paulo, n. 75, 2012. Disponível em: http://revistapiaui.estadao.com.br/edicao-75/anais-do-sertao/era-uma-vez-a-transposicao. Acesso em: 13 set. 2015.

ZELLHUBER, A.; SIQUEIRA, R. Rio São Francisco em descaminho: degradação e revitalização. Cadernos do CEAS, Salvador, n. 227, p. 7-34, jul./set. 2007. 